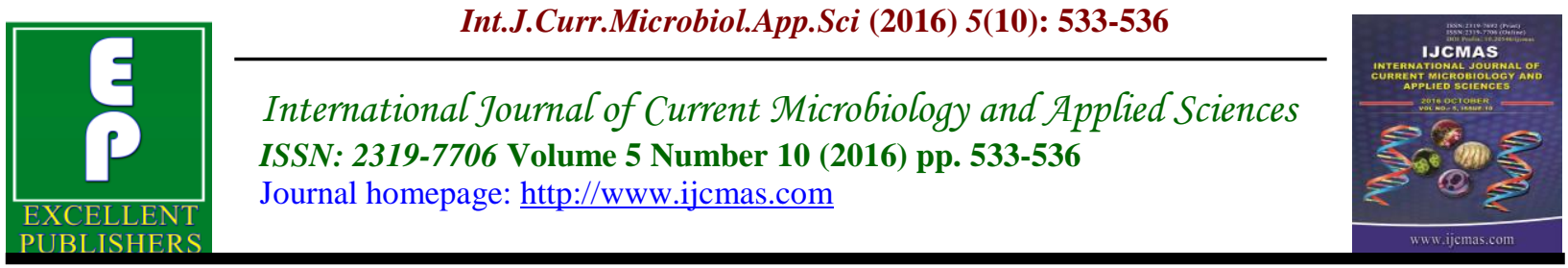

Original Research Article

http://dx.doi.org/10.20546/ijcmas.2016.510.059

\title{
Efficacy of Procalcitonin as a Marker of Acute Inflammation in Patients of Suspected Bacterial Sepsis
}

\author{
Tariq Ahmad Shah*, Vidya Pai and Jitendra Chandra Devrari \\ Department of Microbiology, YMC, Mangalore, India \\ *Corresponding author
}

\begin{abstract}
A B S T R A C T
Keywords

Procalcitonin,

Sepsis,

Blood culture,

Bacterial

Sepsis

Article Info

Accepted:

20 September 2016

Available Online:

10 October 2016

Bacteraemia is associated with high morbidity and mortality. Sepsis is the second most common cause of death after myocardial infarction in patients admitted to intensive care units. Time to detection and treatment decides the outcome.There is a constant exploration for biomarkers of sepsis. Aim of the present study was to determine procalcitonin levels in patients with suspected sepsis and its correlation with blood culture positivity. Blood culture and procalcitonin levels were done in 116 inpatients of our teaching hospital, which were suspected to have sepsis. Among 116 patients of suspected sepsis, 13 patients had a positive blood culture $(11.20 \%)$. Procalcitonin levels of 12 of proven sepsis patients was positive $(>0.5$ $\mathrm{ng} / \mathrm{ml})$. The sensitivity, specificity, the PPV and the NPV of Procalcitonin were $92.85 \%, 95.37 \%, 72.22 \%$ and $99.03 \%$ respectively. Procalcitonin is a promising biomarker in sepsis. Especially the high negative predictive value of PCT, can avoid unwarranted use of antibiotics.
\end{abstract}

\section{Introduction}

Bacteraemia is the presence of viable bacteria in the blood stream. Blood is normally a sterile environment, so detection of bacteria in blood is always anomalous. Bacteremia is the principal means by which local infections spread to distant organs. Bacterial sepsis is associated with high morbidity and mortality. Sepsis is the second most common cause of death after myocardial infarction in patients admitted to intensive care units (Nanda et al., 2016).

There is a constant exploration for biomarkers of sepsis. Some of the biomarkers that have been evaluated include lactate, interleukins, $\mathrm{C}$ reactive protein (CRP), Absolute Neutrophil count, Absolute band count, ESR, cytokines like IL-1, IL-6, TNF and procalcitonin (Harbarth et al., 2001).

Procalcitonin (PCT) is a peptide precursor of hormone calcitonin (CT) and a cytokine mediator composed of 116 amino acids. PCT is synthesized by the parafollicular cells of thyroid (c cells), neuroendocrine cells of lungs and intestines. It is produced ubiquitously in response to endotoxin or to mediators released in response to bacterial infections. Procalcitonin is found in serum 
of normal persons, usually below $0.1 \mathrm{ng} / \mathrm{ml}$ (Shun Yuan et al., 2016).

The significance of serum PCT concentration was reported in 1993 by Assicot et al., (1993). Since then there have been many studies investigating its role in differentiating and risk-stratifying the infectious and noninfectious disease processes.

The present study was carried to determine procalcitonin levels in patients with suspected sepsis and its correlation with blood culture positivity.

\section{Materials and Methods}

The prospective study was done in a tertiary care teaching hospital. 116 patients of suspected bacterial sepsis, who were admitted as inpatients were included as study subjects over a period between August 2015 and April 2016. With aseptic precautions, 5- $10 \mathrm{ml}$ blood was collected from ante cubital fossa. $2 \mathrm{ml}$ was collected in plain tubes and the remaining was inoculated into Sterile BHI broth. Blood culture was done by conventional method as per standard protocol. BHI Broth bottles with sample were incubated for 7 days on $37^{\circ} \mathrm{C}$ and subculture were done on5\% sheep blood agar, MacConkey agar plates after overnight, 3 days and 5-7 days. Bacteria were identified based on their colonial morphology and biochemical reactions by bacterial standardized techniques. Antimicrobial susceptibility test was done by Kirby Bauer disc diffusion method and interpreted according to CLSI guidelines (Performance standards for antimicrobial susceptibility testing, 2016).

Procalcitonin levels in serum sample were estimated by Immunochromatographic method using the commercially available point of care test kit, B.R.A.H.M.S, PCT-Q, (Thermo-Scientific). The test was done as per manufacturer's instructions provided with the kit. After 30 minutes the PCT concentration range of the sample was determined by comparing the colour intensity of the test band with the colour blocks of the reference.

According to the manufacturers, a value of PCT $>0.5 \mathrm{ng} / \mathrm{ml}$ was taken as pathological, 0.5 to $2 \mathrm{ng} / \mathrm{ml}$ indicated that systemic infection could not be ruled out, 2 to 10 $\mathrm{ng} / \mathrm{ml}$ indicated greater chances of sepsis and a value of PCT above $10 \mathrm{ng} / \mathrm{ml}$ indicated severe bacterial sepsis.

\section{Results and Discussion}

Out of 116 samples, 13 patients, showed evidence of bacteremia by blood culture, and 12 of these had a Procalcitonin level of more than $0.5 \mathrm{ng} / \mathrm{mL} .99$ samples showed Procalcitonin values less than $0.5 \mathrm{ng} / \mathrm{mL}$, and 1 among these was culture positive and rest were culture negative shown in table 1 With a threshold of $0.5 \mathrm{ng} / \mathrm{mL}$ for Procalcitonin, sensitivity and specificity for the Procalcitonin assay were $92.85 \%$ and $95.37 \%$, respectively. The positive predictive value was $72.22 \%$ and the negative predictive value $99.03 \%$ compared with blood cultures. Serum levels of Procalcitonin in all the study patients are shown in table 2 .

Rapid identification of infection has a major impact on the clinical course, management, and outcome of critically ill patients. Though blood culture is considered the gold standard test method for diagnosing septicaemia, this method lacks sensitivity and is time consuming, and contamination by skin microorganisms can be problematic. The diagnosis of bacteraemia in patients presenting with fever has been reliant on a combination of clinical examination and laboratory parameters, such as CRP level, total counts and erythrocyte sedimentation rate (ESR). However, these parameters lack 
accuracy for early diagnosis of bacteraemia. Procalcitonin (PCT) is a peptide precursor of hormone calcitonin (CT), that has a role in calcium homeostasis. All tissues in the human body have the capacity to express PCT. Bacterial cell wall products and the endotoxins provoke the production of PCT from the parenchyma tissues. The tissue cells do not have the ability to convert PCT to Calcitonin. As a result of response to infection also PCT is secreted. Hence there is a rise in the serum levels of PCT in bacterial infections (Kenneth et al., 2010).

Ever since 1993, Procalcitonin has been studied expansively, as it was described as a marker that signals the extent of systemic inflammation. Several studies have reported the usefulness of PCT in sepsis, meningitis, respiratory tract infections, urinary tract infections and burns, used alone or in combination with other markers like CRP and Absolute neutrophil count.
In the present study, with a cut off of $>0.5$ $\mathrm{ng} / \mathrm{ml}$ as an indicator of sepsis, the sensitivity, the specificity, the PPV and the NPV was found to be $92.85 \%, 95.37 \%$, $72.22 \%$ and $99.03 \%$. The sensitivity and specificity were reported as $90 \%$ and $84 \%$ respectively with the same cut off by Sinha et al., (2011) Whereas Nanda et al., (2009) have reported a sensitivity, specificity, the PPV and the NPV at the same cut-off as $85.7 \%, \quad 25.4 \%, \quad 11.7 \%$ and $93.9 \%$ respectively.

Several other studies have reported sensitivity and specificity of PCT in systemic inflammatory response syndrome, neonatal sepsis etc. The sensitivity varies from $85 \%$ to $97 \%$ and specificity reported as low as $25 \%$ to as high as $94.7 \%$. Reports from other investigators and our study, point towards, a very high negative predictive value of PCT $(93.7 \%)$. Hence a PCT assay will avoid unjustifiable usage of antibiotics.

Table.1 Correlation between Procalcitonin and blood culture positivity

\begin{tabular}{|l|l|l|l|}
\hline Test & $\begin{array}{l}\text { Blood culture } \\
\text { positive }\end{array}$ & $\begin{array}{l}\text { Blood culture } \\
\text { negative }\end{array}$ & Total \\
\hline Procalcitonin positive & 12 & 05 & 17 \\
\hline Procalcitonin negative & 1 & 98 & 99 \\
\hline Total & 13 & 103 & 116 \\
\hline
\end{tabular}

Table.2 Serum levels of Procalcitonin and blood culture results

\begin{tabular}{|l|c|c|c|c|}
\hline PCT values & $<0.5 \mathrm{ng} / \mathbf{m L}$ & 0.5 to $2 \mathrm{ng} / \mathrm{ml}$ & 2 to $10 \mathrm{ng} / \mathrm{ml}$ & $>10 \mathrm{ng} / \mathrm{ml}$ \\
\hline Blood culture positive & 01 & --- & 04 & 08 \\
\hline Blood culture negative & 98 & 04 & 01 & --- \\
\hline Total & 99 & 04 & 05 & 08 \\
\hline Grand Total & 116 & \multicolumn{4}{|l}{} \\
\hline
\end{tabular}

Five out of 116 patients had PCT levels > $0.5 \mathrm{ng} / \mathrm{ml}$ and blood culture negative. Of these 4 had PCT values between 0.5 and 2 $\mathrm{ng} / \mathrm{ml}$ and only one had a level $2-10 \mathrm{ng} / \mathrm{ml}$. This could probably be due to low levels of Bacteremia and bacteria failed grow in culture or anaerobic bacterial infection or patients had some other cause of inflammation. One patient showed < $0.5 \mathrm{ng} / \mathrm{ml}$ PCT levels (negative) but his blood culture grew an organism. Probable reason could be the blood culture growth 
being a skin flora contaminant or an empiric antibiotic was started prior to blood culture resulting in reduction in inflammation and hence the PCT values.

In conclusion, bacterial sepsis is an emergency that requires specific antimicrobial therapy and at the same time often difficult to diagnose clinically. A delayed recognition of the condition may lead to poor outcome and meanwhile over diagnosis may lead to unnecessary use of antibiotics. PCT level could be a reliable marker to rule out or predict bacteraemia in patients of bacterial sepsis, and therefore, help in deciding the appropriate use of antimicrobial agents. Furthermore, negative PCT test can help to protect against emerging antimicrobial-resistant strains by restricting unnecessary antibiotic use. More prospective and large-scale studies are needed to better define the usefulness of PCT levels in various clinical settings.

\section{Acknowledgement}

The authors highly acknowledge Department of Microbiology, Yenepoya Medical College, Mangalore, India.

\section{References}

Assicot, M., Gendrel, D., Carsin, H., Raymond, J., Guilbaud, J., Bohuon, C. 1993. High serum Procalcitonin concentrations in patients with sepsis and infection. Lancet, 341: 515-8.

Harbarth, S., Holeokova, K., Froidevaux, C., Pittet, D., Ricou, B., Grau, G.E. 2001. Diagnostic value of Procalcitonin, interleukin 6 and interleukin 8 in critically ill patients admitted with suspected sepsis. Am. J. Respir. Crit. Care Med., 164: 396402.

Kenneth, L.B., Snider, R., Nylen, E.S. 2010. Procalcitonin in sepsis and systemic inflammation: a harmful biomarker and a therapeutic target. British J. Pharmacol., 159: 253-264.

Nanda, S.K. and Suresh, D.R. 2009. Plasma Lactate as prognostic marker of septic shock with acute respiratory distress syndrome. Indian J. Clin. Biochem., 24: 433-435.

Nanda, S.K., Dinakaran, A., Bhat, S.K., Ravichandran, Kanungo, R. 2016. Diagnostic and prognostic role of Procalcitonin in sepsis in a tertiary care hospital. Biomed. Res., 27(1): 79-83.

Nargis, W., Ibrahim, M., Ahamed, B.U., Ahmed, M., Ara, N. 2011. Utility Of Procalcitonin As A Diagnostic And Prognostic Biomarker Of Sepsis In Comparison To Culture \& Other Inflammatory Markers, 5(2): 5-15.

Performance standards for antimicrobial susceptibility testing. twenty six informational supplements.2016. Clinical and Laboratory Standard Institute document. 36(1): M100-S26.

Shun Yuan Guo, Yin Zhou, Qing Feng $\mathrm{Hu}$, Jiong Yao and Hong Wang. 2015. Procalcitonin Is a Marker of GramNegative Bacteremia in Patients With Sepsis. The American J. Med. Sci., 349(6): 499-504.

Sinha, M., Desai, S., Mantri, S., Kulkarni, A. 2011. Procalcitonin as an adjuvant marker in sepsis. Indian J. Anaesthesia, 55: 266270.

\section{How to cite this article:}

Tariq Ahmad Shah, Vidya Pai and Jitendra Chandra Devrari. 2016. Efficacy of Procalcitonin as a Marker of Acute Inflammation in Patients of Suspected Bacterial Sepsis. Int.J.Curr.Microbiol.App.Sci. 5(10): 533-536. doi: http://dx.doi.org/10.20546/ijcmas.2016.510.059 